Rafael Vitor Guerra Queiroz

\title{
Estudo sobre a criatividade em matemática
}

Dissertação apresentada como requisito parcial para obtenção do grau de Mestre pelo Programa de Pós-graduação em Matemática, do Departamento de Matemática da PUC-Rio.

Orientadora : $\quad$ Prof ${ }^{a}$ Renata Martins Rosa Coorientadora: Prof ${ }^{a}$ Silvana Marini Rodrigues Lopes 


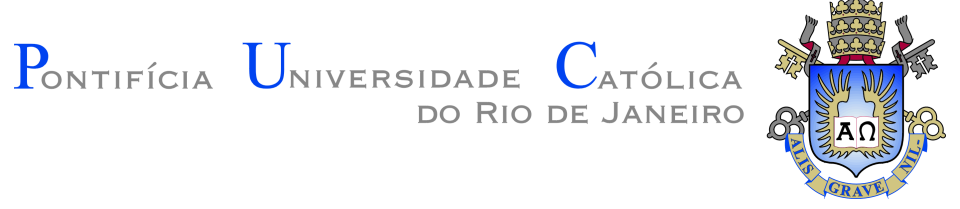

Rafael Vitor Guerra Queiroz

Estudo sobre a criatividade em matemática

Dissertação apresentada como requisito parcial para obtenção do grau de Mestre em Matemática pelo Programa de Pósgraduação em Matemática, do Departamento de Matemática da PUC-Rio Aprovada pela Comissão Examinadora abaixo:

Prof ${ }^{a}$ Renata Martins Rosa

Orientadora

Departamento de Matemática - PUC-Rio

Profa Silvana Marini Rodrigues Lopes

Coorientadora

EscolaMat

Prof ${ }^{a}$ Christine Sertã Costa

Departamento de Matemática - PUC-Rio

Profa Flávia dos Santos Soares

Faculdade de Educação - UFF

Rio de Janeiro, 24 de Setembro de 2021 
Todos os direitos reservados. A reprodução, total ou parcial do trabalho, é proibida sem a autorização da universidade, do autor e do orientador.

\section{Rafael Vitor Guerra Queiroz}

Mestre e graduado em Engenharia Mecânica pelo Instituto Militar de Engenharia (IME-RJ). Professor da rede particular de ensino.

Ficha Catalográfica

Queiroz,Rafael Vitor Guerra

Estudo sobre a criatividade em matemática / Rafael Vitor Guerra Queiroz; orientadora: Renata Martins Rosa; coorientadora: Silvana Marini Rodrigues Lopes. - 2021.

43 f: il. color. ; $30 \mathrm{~cm}$

Dissertação (mestrado) - Pontifícia Universidade Católica do Rio de Janeiro, Departamento de Matemática, 2021.

Inclui bibliografia

1. Matemática - Teses. 2. Criatividade. 3. Criatividade em matemática. I. Rosa, Renata Martins. II. Lopes, Silvana Marini Rodrigues. III. Pontifícia Universidade Católica do Rio de Janeiro. Departamento de Matemática. IV. Título. 
Aos meus amados filhos: João Marcos, Antônio e Catarina. 


\section{Agradecimentos}

À minha esposa Flavia, pelo apoio durante todo o mestrado. Os frutos deste trabalho também são seus.

Aos primeiros professores de minha vida, Helcio e Sofia, e meu primeiro amigo de turma, Lucas.

Aos meus sogros Paulo e Carla, pela atenção e apoio, que nesta fase foram imprescindíveis para a conclusão deste trabalho.

A todos os professores do PROFMAT da PUC, que propiciaram uma experiência engrandescedora neste mestrado.

À Deus, que "restaura as forças de minha alma e pelos caminhos retos me leva, por amor de seu nome".

O presente trabalho foi realizado com apoio da Coordenação de Aperfeiçoamento de Pessoal de Nível Superior - Brasil (CAPES) - Código de Financiamento 001. 


\section{Resumo}

Queiroz,Rafael Vitor Guerra; Rosa, Renata Martins; Lopes, Silvana Marini Rodrigues. Estudo sobre a criatividade em matemática. Rio de Janeiro, 2021. 43p. Dissertação de Mestrado - Departamento de Matemática, Pontifícia Universidade Católica do Rio de Janeiro.

Este trabalho tem por finalidade fazer um estudo sobre a criatividade. Inicialmente, faz-se uma revisão sobre o conceito de criatividade e criatividade em matemática. Em seguida, são apresentados fatores que possivelmente influenciam no seu desenvolvimento. Por fim, são apresentadas atividades para sala de aula para favorecer o desenvolvimento da criatividade em matemática em alunos do Ensino Básico.

\section{Palavras-chave}

Criatividade; Criatividade em matemática. 


\section{Abstract}

Queiroz,Rafael Vitor Guerra; Rosa, Renata Martins (Advisor); Lopes, Silvana Marini Rodrigues (Co-Advisor). Study about creativity in mathematics. Rio de Janeiro, 2021. 43p. Dissertação de Mestrado - Departamento de Matemática, Pontifícia Universidade Católica do Rio de Janeiro.

This work aims to study creativity.Initially, there is a review of the concept of creativity and creativity in mathematics. Then, factors that possibly influence its development are presented. Finally, classroom activities are presented to encourage the development of creativity in mathematics in Basic Education students.

\section{Keywords}

Creativity; Creativity in mathematics. 


\section{Sumário}

1 Introdução 13

2 Fundamentação teórica $\quad 15$

$\begin{array}{lll}2.1 & \text { A criatividade } & 15\end{array}$

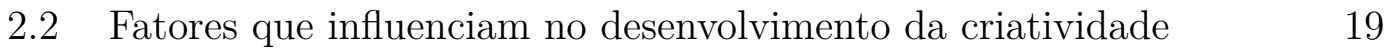

2.3 A criatividade em matemática 21

2.4 Instrumentos para o desenvolvimento da criatividade em matemática 23

$\begin{array}{lll}2.4 .1 & \text { Resolução de problemas } & 24\end{array}$

$\begin{array}{lll}2.4 .2 & \text { Formulação de problemas } & 26\end{array}$

$\begin{array}{lll}2.4 .3 & \text { Redefinição } & 27\end{array}$

$3 \quad$ Exercitando a criatividade em matemática dos alunos $\quad 29$

3.1 Produções escritas 29

3.2 Produções numéricas ou algébricas 30

3.3 Representações gráficas e construções geométricas 31

$\begin{array}{ll}\text { Referências } & 40\end{array}$ 


\section{Lista de figuras}

$\begin{array}{lll}\text { Figura 2.1 Henrí Poincaré. } & 16\end{array}$

Figura 3.1 Respostas comuns para o país dos meios 33

Figura 3.2 Resposta incomum para o país dos meios 33

Figura 3.3 Respostas comuns para o país dos terços e dos quartos 33

Figura 3.4 Respostas incomuns para o país dos terços e quartos 33 


\section{Lista de tabelas}

Tabela 2.1 Diferenças entre triângulo e pirâmide. 


\section{Lista de Abreviaturas}

BNCC - Base Nacional Comum Curricular

PCN - Parâmetros Curriculares Nacionais 
Saiba fazer uma tese e admirar uma aurora, mergulhar em abstrações profundas e, como o Divino Mestre, brincar com as crianças.

Antonin-Gilbert Sertilanges, A vida intelectual. 


\section{Introdução}

A necessidade de se desenvolver as habilidades criativas do estudante da Educação Básica surge da importância da criatividade para a resolução de problemas. De fato, pessoas criativas possuem capacidade de apresentar soluções inovadoras para os problemas da sociedade e lidar com os desafios sociais e tecnológicos da atualidade, de acordo com Gontijo [1; 2]. A criatividade, portanto, é uma habilidade imprescindível para o crescimento científico, tecnológico e econômico de um país.

No âmbito da Educação Básica, a Base Nacional Comum Curricular (BNCC) apresenta como uma das competências gerais da Educação Básica:

Exercitar a curiosidade intelectual e recorrer à abordagem própria das ciências, incluindo a investigação, a reflexão, a análise crítica, a imaginação e a criatividade, para investigar causas, elaborar e testar hipóteses, formular e resolver problemas e criar soluções (inclusive tecnológicas) com base nos conhecimentos das diferentes áreas [3] (grifo nosso).

Nas suas orientações para o Ensino Fundamental, os Parâmetros Curriculares Nacionais, ou PCN, destacam que o trabalho com a Matemática deve contribuir para que os alunos sejam capazes de:

Questionar a realidade formulando-se problemas e tratando de resolvêlos, utilizando para isso o pensamento lógico, a criatividade, a intuição, a capacidade de análise crítica, selecionado procedimentos e verificando sua adequação [4].

Este documento também destaca que:

O ensino de Matemática prestará sua contribuição à medida que forem exploradas metodologias que priorizem a criação de estratégias, a comprovação, a justificativa, a argumentação, o espírito crítico, e favoreçam a criatividade, o trabalho coletivo, a iniciativa pessoal e a autonomia do desenvolvimento da confiança na própria cacpacidade de conhecer e enfrentar desafios [4].

Em relação ao Ensino Médio, os PCN indicam que o trabalho com a Matemática tem por objetivo "desenvolver as capacidades de raciocínio e resolução de problemas, de comunicação, bem como o espírito crítico e criativo [5]". Os mesmos PCN sinalizam que o ensino da Matemática, em 
sua organização curricular, deve exercer dois papéis: um formativo e outro instrumental. O papel formativo tem por objetivo:

Formar no aluno a capacidade de resolver problemas de investigação genuínos, gerando hábitos de investigação, proporcionando confiança e desprendimento para analisar e enfrentar situações novas, propiciando a formação de uma visão ampla e científica da realidade, a percepção da beleza e da harmonia, o desenvolvimento da criatividade e o de outras capacidades pessoais [5].

O papel instrumental, por sua vez, destina-se a ensinar técnicas e estratégias para serem aplicadas nas diversas ciências para a resolução de problemas, contribuindo para o avanço do conhecimento.

Observa-se que a BNCC e os PCN [3; 4; 5], que orientam a educação brasileira e particularmente o ensino da matemática, citam a criatividade como uma importante habilidade a ser exercitada pelo aluno. Neste cenário, a escola desempenha um importante papel no desenvolvimento da criatividade. Torre (2005), citado por Gontijo [2], diz que a riqueza de um país não está apenas em seus recursos naturais, mas também na capacidade inovadora e criativa das gerações mais jovens. Para a formação de jovens mais criativos e com capacidade de apresentar soluções inovadoras, torna-se necessário incentivar o seu potencial criativo desde a educação básica [6]. Apesar disso, o exercício da criatividade não se mostra como um processo fácil, tendo em vista que depende de processos psicológicos complexos, e também pela dificuldade em definir criatividade, que pode variar de acordo com fatores históricos, econômicos e sócio-culturais. Cabe ainda destacar que práticas comuns nas escolas, como a de se trabalhar com problemas que admitem uma única solução, classificar respostas como certas ou erradas e evitar que os alunos cometam erros em suas soluções desencorajam os discentes a explorarem ideias novas, comprometendo o seu potencial criativo $[7 ; 8 ; 9]$. Para o desenvolvimento do potencial criativo do aluno, é necessário que o professsor incetive experiências para os alunos como trabalharem com problemas que admitem diversas soluções ou métodos de resolução e solucionarem problemas por mais de uma forma. Nesse contexto, é importante que o professor crie em sala de aula um ambiente propício para que os alunos possam expressar suas ideias e se sintam motivados [9].

Este trabalho tem por finalidade fazer um estudo sobre a criatividade em matemática. Inicialmente, faz-se uma revisão bibliográfica sobre o conceito de criatividade e criatividade em matemática. Em seguida, são propostas atividades para favorecer o desenvolvimento da criatividade em matemática em alunos da Educação Básica. 


\section{2}

\section{Fundamentação teórica}

\section{1}

\section{A criatividade}

O conceito de criatividade se mostra muito complexo, uma vez que varia de uma sociedade para outra, estando longe de ser consensual o que se entende por produtos criativos, mesmo entre os especialistas [10]. Não há um conceito exato de criatividade, unânime ou globalmente aceito; ao invés, são várias as definições disponíveis nas literaturas, apresentando pontos em comum e enfatizando diferentes aspectos relacionados com esta habilidade. Por exemplo, Karckockiene [11] relaciona a criatividade com a capacidade de inovação. No entanto, autores como Berghetto (2013), citado por Kim [12], argumentam que a inovação não é suficiente para que seja considerada um produto criativo, exigindo que esta possua outros atributos, como relevância e utilidade.

A criatividade foi abordada de uma maneira geral por filósofos da Antiguidade e da Idade Moderna: para Platão (428 a.C. - 348 a.C.), a criatividade é uma espécie de loucura ou uma inspiração divina. Para Kant (1724 - 1804), criatividade se relaciona com a imaginação [13].

No século XX, observa-se que a maioria dos trabalhos sobre criatividade foram escritos por psicólogos, seguido dos filósofos [13]. No entanto, a primeira pesquisa a chamar a atenção para o processo criativo não foi de um psicólogo ou filósofo, mas sim de um matemático: Henrí Poincaré (1854-1912). O trabalho de Poincaré, com o título An Inquiry into the working methods of mathematicians, foi publicado em 1902 e tinha por objetivo conhecer como os matemáticos da época percebiam o processo de criação em Matemática, e quais fatores contribuíam nesse processo.

Em seu trabalho, Poincaré descreve as etapas da criação matemática, iniciando em uma fase na qual o matemático realiza um trabalho consciente e árduo, seguido de um período em que o problema é deixado de lado (trabalho inconsciente), ocorrendo depois de uma "iluminação", e por fim, uma etapa de verificação [13].

Poincaré observou, ainda, que os matemáticos tenderiam a apresentar dois tipos de "espírito": uns preocupados com a lógica (denominados analistas), 
e outros guiados pela intuição (denominados geômetras) [14]. Os primeiros são incapazes de "ver no espaço", enquanto os segundos se cansam dos longos cálculos. Todavia, Poincaré destacou a importância de ambos os tipos de matemáticos para o progresso da ciência.

Em uma palestra ministrada no Institute Général Psychologique em 1908 sobre o processo de criação em matemática, depois de publicado o seu artigo, Poincaré afirmou que "a gênese da invenção matemática é um problema que deve inspirar o mais vivo interesse ao psicólogo"[13].

Figura 2.1: Henrí Poincaré.

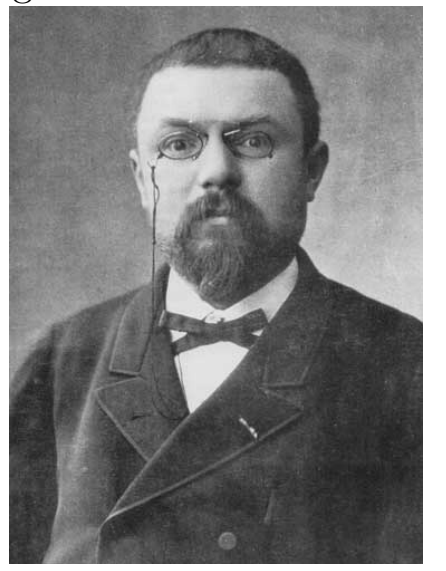

Fonte: disponível em:

<https://www.escritas.org/autores/henri-poincare.jpg >. Acesso em: 27 mai 2021.

Em 1944, o matemático Jacques Hadamard proferiu uma série de palestras na École Libres des Hautes Études em Nova Iorque, seguido da publicação de um livro sobre a psicologia da criação no campo da matemática:

O nosso título é "A psicologia da invenção no campo da matemática", e não "Psicologia da invenção matemática". Pode ser interessante lembrar que a invenção matemática não é mais que um caso de invenção em geral, um processo que pode ocorrer em vários domínios, seja em ciência, literatura e arte e também em tecnologia. [15].

Com isso, Jacques Hadamard afirma que a criatividade não é uma habilidade restrita ao campo da matemática, abrangendo muitas outras áreas do conhecimento. A criatividade é uma habilidade do intelecto humano, que permeia os diversos campos do conhecimento, de modo que é possível observar um trabalho criativo na arte, na música, na produção tecnológica, dentre outros.

Hadamard afirma, ainda, sobre o processo criativo dos estudantes: 
Entre o trabalho do estudante que tenta resolver um problema em Geometria ou Álgebra e o trabalho de criação, pode-se dizer que existe apenas uma diferença em grau, uma diferença em nível, ambos os trabalhos sendo de natureza semelhante [15].

Em 1950, Guilford definiu a criatividade de acordo com as seguintes características: fluência, flexibilidade, originalidade, síntese, análise, reorganização e redefinição, complexidade, e elaboração. Essas características são denominadas características latentes da criatividade, e as três primeiras, que serão abordadas nesse trabalho, serão explicadas adiante.

ord destacou, ainda, dois processos que levam à criatividade: pensamento divergente (que gera muitas ideias) e o pensamento convergente (que escolhe e desenvolve uma determinada ideia). Além disso, ord foi o primeiro a propor que a criatividade poderia ser avaliada de forma quantitativa e objetiva, a partir de então, vários métodos de avaliação de criatividade foram desenvolvidos.

A partir da década de 1980, há muitos estudos que envolvem conceitos e modelos sobre a criatividade. São apresentados a seguir alguns deles. Essa lista é apresentada para constatar que há diferentes conceitos de criatividade, que destacam aspectos importantes dessa habilidade:

1. Em 1988, Mumford \& Gustafson [16] definem a criatividade como a habilidade em resolver problemas.

2. Em 1996, Mihaly Csikszentmihalyi apresenta o modelo de perspectiva de sistemas, afirmando que "a criatividade não ocorre dentro dos indivíduos, mas é resultado da interação entre os pensamentos do indivíduo e o contexto sócio-cultural. Criatividade deve ser compreendida não como um fenômeno individual, mas como um processo sistêmico"[17]. Para Mihaly, os estudos em criatividade devem focar não somente no indivíduo, mas também de seu meio social e histórico.

3. Em 1997, Silver [18], contrariando o pensamento de que a criatividade é uma iluminação alcançável por poucos "gênios", afirma que a criatividade está relacionada com um saber profundo e flexível de um domínio específico, associado com um esforço individual (longos períodos de trabalho e reflexão) e influências instrucionais.

4. Em 1999, Sternberg \& Lubart, citados por Vincent-Lancrin et al [19], definem a criatividade como a habilidade de produzir algo que seja original e apropriado. Dessa forma, não basta criar algo novo, mas algo que seja adequado para o contexto. Entende-se por "adequado para o contexto"uma produção que obedece às limitações, regras e restrições impostas. 
5. Em 2000, Lubart, citado por Vincent-Lancrin et al [19], define a criatividade como uma sequência de pensamentos e ações que levam a uma produção original.

6. Em 2001, Amabile concorda com a definição de criatividade como a produção de ideias novas, que seguem um propósito, que têm sentido e são orientadas para um objetivo. Porém, ela afirma que esta definição não contribui para o processo de determinar, medir e avaliar a criatividade. Assim, para desenvolver suas pesquisas, Amabile criou uma definição que chamou de técnica consensual de avaliação, uma vez que a criatividade é definida em função de uma avaliação por especialistas. Ou seja, esta definição é baseada no pressuposto de que as pessoas experientes num determinado campo sabem reconhecer um trabalho criativo deste campo, mesmo que não saibam exprimir as características que o tornam criativo. Assim, a técnica consensual consiste em submeter um trabalho de um determinado campo de interesse a um grupo de avaliadores, especialistas naquele campo e que classificam o trabalho numa escala numérica de acordo com sua dimensão criativa. Este método pode ser aplicado em diferentes domínios: na criatividade artística verbal, resolução de problemas e vários outros.

7. Em 2004, Boden [20] afirma que a criatividade é a habilidade de produzir ideias e artefatos que são novos, surpreendentes e úteis. Boden distingue a criatividade histórica (quando ninguém teve a ideia antes) da criatividade psicológica (uma ideia original para um indivíduo).

8. Em 2009, Beghetto\&Kaufman (2009), citado por Papaleontiou-louca [21], distingue a criatividade "grande C"e criatividade "pequeno c". A criatividade "grande C", ou criatividade absoluta, é aquela que produz resultados até então desconhecidos e que adquirem grande importância para a comunidade científica. Essa criatividade é aquela de pessoas eminentes ou gênios. E a criatividade "pequeno c", ou criatividade relativa, é aquela que produz resultados novos para a pessoa que descobriu ou para um determinado grupo, como em uma sala de aula. É a criatividade "pequeno c"que justifica o estímulo à criatividade na educação.

Apesar dos diferentes conceitos de criatividade apresentados, que focam em aspectos distintos como resolução de problemas, criação de novas ideias, produção de algo apropriado para o contexto, é possível identificar, nessas diferentes definições, características importantes para o desenvolvimento cog- 
nitivo do indivíduo e sua atuação na sociedade, destacando a importância de valorizar o trabaho da criatividade no ambiente escolar.

Diversos autores comentam sobre a importância do exercício da criatividade. Em 2014, Papaleontiou-louca afirma, sobre o exercício da criatividade na educação:

"Argumentamos aqui que a criatividade na educação é não somente essencial, mas também vital para promover a oportunidade de nossos estudantes de estender seus conhecimentos e dar-lhes a chance e a possibilidade de criar novos conhecimentos e ideias [21]."

Em 2006, Sternberg afirma a importância do exercício da criatividade por meio da educação:

"Podemos ensinar os estudantes a pensar de forma mais criativa [...] Motivando este trabalho está a crença de que os sistemas em muitas escolas tendem a favorecer as crianças com potencial em memória e habilidades analíticas [8]."

Em 1997, Silver afirma que a criatividade é uma habilidade que pode ser exercitada em sala de aula, e de suma importância no ensino:

"A visão contemporânea de criatividade também sugere que pessoas que são criativas em um domínio demonstram possuir uma disposição criativa ou uma orientação à sua atividade nesse domínio. Isto é, a atividade criativa resulta de uma inclinação a pensar e a se comportar criativamente. Essa nova visão de criatividade fornece uma fundamentação muito mais forte para construir aplicações educacionais. De fato, essa visão sugere que uma formação rica em criatividade deva ser apropriada para uma larga faixa de estudantes, e não meramente para uns poucos indivíduos excepcionais [18] (grifo nosso)."

\section{2}

\section{Fatores que influenciam no desenvolvimento da criatividade}

Apesar de sua importância, o exercício da criatividade não se mostra como um processo fácil, tendo em vista que depende de diversos fatores. Nessa seção, são apresentados alguns fatores que influenciam no seu exercício e desenvolvimento:

a) O ambiente: a criatividade sofre influência do ambiente, que pode incentivar ou não o pensamento criativo do aluno [22]. Thistlewaite (1963), Knapp (1963) e Torrance (1965), citados por Alacapinar [23], afirmam que um ambiente que crie oportunidades para o pensamento criativo, encorajando alunos para expressar suas ideias, é fundamental para o desenvolvimento da criatividade. No ambiente, é fundamental que o aluno se sinta acolhido, tendo suas contribuições valorizadas, para que sinta confiança para se expressar. 
Um ambiente que valorize o cometimento de erros pelos alunos é fundamental para o desenvolvimento da criatividade. Pensamentos que trazem em si uma visão negativa do erro são prejudiciais. Ao contrário, os erros são fundamentais para que o professor entenda o raciocínio do aluno, auxiliando na sua correção ou mostrando formas de pensamento que podem também estar corretas.

O erro faz parte do processo de investigação da pesquisa matemática, na qual são testadas hipóteses. Também na pesquisa científica, na qual o método científico prevê aceitação ou rejeição de hipóteses pelos erros observados. Observa-se, portanto, a importância do erro na atividade de pesquisa.

Jo Boaler, baseada em pesquisas de Jason Moser et al [24] e Mangels et e al.[25] com estudantes, diz que o cérebro dos estudantes reagiu com mais atividades elétricas quando cometeram erros do que quando acertaram. Além disso, o estudo observou que a atividade cerebral era maior depois do erro nos alunos que não tinham uma mentalidade fixa sobre sua inteligência.

b) Concessão de prêmios: não há um consenso quanto à importância da concessão de prêmios pelas produções criativas para o desenvolvimento da criatividade. Alguns estudos mostram que a concessão de prêmios pode favorecer o desenvolvimento criativo [23], no entanto, outras pesquisas mostram que essa concessão pode ser prejudicial [16].

Amabile [26] estudou os efeitos que recompensas possuem sobre a criatividade. Em suas pesquisas, ela observou que a criatividade está fortemente relacionada à motivação intrínseca das pessoas, isto é, aquela despertada pelo interesse, prazer, satisfação e desafio proporcionados pelo trabalho. As recompensas, por sua vez, têm um enorme poder de diminuir a motivação interna das pessoas e, quando isso ocorre, há um declínio também da criatividade.

c) Apoio dos amigos, pais e professores: Alacapinar [23] analisou a criatividade de estudantes, destacando um aumento da criatividade entre alunos que recebiam apoio de seus amigos, familiares e professores em suas ideias e produções relacionadas à criatividade. Dessa forma, Alacapinar recomenda que, para o desenvolvimento da criatividade dos alunos, pais e professores fossem orientados a incentivar as habilidades criativas dos alunos.

d) Conhecimento do aluno: observa-se que a familiaridade e o domínio de uma determinada área influenciam na produção criativa nesta mesma área. Neste contexto, há duas correntes: a "foundation view", que considera que o conhecimento e a familiaridade se relacionam positivamente com a criatividade, e a "tension view", que afirma que há um limite na quantidade de conhecimento e familiaridade necessários para promover a criatividade [27]. Weisberg (1999), citado por Pinho [13] afirma que o conhecimento é um ponto de partida e está 
relacionado de forma positiva com a criatividade. Para Weisberg, para uma pessoa se tornar mais criativa, necessita de tempo para o amadurecimento de seus conhecimentos.

e) Anos escolares: muitas pesquisas foram feitas avaliando sobre a contribuição dos anos escolares no desenvolvimento da criatividade do aluno. Runco [28] afirma que a criatividade aumenta gradualmente com o passar dos anos escolares, com o amadurecimento do aluno e suas experiências vividas em ambiente escolar ou não. Torrance (1968), citado por Claxton et al [29], mostrou que a criatividade de alunos sofre uma queda no $4^{\circ}$ ano do ensino fundamental, apresentando a seguir um crescimento, fenômeno conhecido por fourth-grade slump. Torrance explica que o fenômeno deve-se ao conformismo que a criança desenvolve no aprendizado da matéria escolar, além da pressão sofrida pelos pais e amigos nos seus resultados, desencorajando os alunos a exibir suas habilidades criativas. Gardner [30] afirma que crianças que acabaram de ingressar na escola possuem uma expressiva criatividade, que sofre uma queda nos primeiros anos escolares, voltando a crescer na adolescência e na fase adulta. Outras pesquisas, como a de Land e Jarman [31], afirmam que a criatividade sofre uma queda contínua.

\section{3}

\section{A criatividade em matemática}

Muitos pesquisadores estabeleceram definições de criatividade em matemática, destacando alguns de seus aspectos[32].

Hadamard, um dos primeiros pesquisadores a estudar a criatividade em matemática, afirma que ela nada mais é do que um caso de invenção em um campo específico, podendo esse processo de criação ocorrer em outras áreas como a arte, a literatura, dentre outros.

Henri Poincaré acreditava que as descobertas na matemática eram fruto da combinação de ideias. Muitas dessas combinações não eram úteis, e Poincaré afirmava que criatividade era identificada quando se distingue e escolhe aquelas que eram importantes.

De maneira análoga, em 1991, Ervynck afirmava que descobrir novos conceitos e relações úteis a partir de relações e conceitos já conhecidos é considerado um sinal da criatividade em matemática. Ervynck acrescenta que a criatividade em matemática desempenha um papel importante no desenvolvimento desta ciência, através do desenvolvimento de novos teoremas $[32]$.

Em 1970, Laycock descreve a criatividade em matemática como a habilidade de analisar um problema em diferentes perspectivas, enxergar padrões, 
diferenças e similaridades, gerar múltiplas ideias e saber escolher um método adequado para resolver problemas matemáticos [32].

Alguns pesquisadores distinguem a criatividade em matemática em um nível profissional e em um nível escolar. No nível escolar, não se espera um trabalho "extraordinário"de criatividade, no entanto, pode-se esperar a visualização de novas ideias, relações e resoluções para um problema matemático [33]. Em 2006, Sriraman propõe esta distinção, definindo a criatividade em matemática em nível profissional como [34]:

1. A habilidade de produzir um trabalho que seja original, não conhecido pela comunidade científica;

2. A habilidade de abrir caminhos para novos questionamentos para outros matemáticos.

E a criatividade em matemática em nível escolar como: [34]:

1. O processo que resulta em novas soluções para um problema matemático;

2. A formulação de novos questionamentos que permitem visualizar um problema em um novo ponto de vista.

Em 2005, Chamberlin e Moon definem a criatitvidade em matemática como uma habilidade de gerar novas soluções para um problema real ou não. Em 2009, Leikin define a criatividade em matemática como uma habilidade própria da mente humana, que pode ser desenvolvida e explorada ou, ao contrário, privada [32]. Ou seja, é possível que a criatividade de um aluno seja prejudicada quando não é trabalhada.

Em 2007, Gontijo afirma que a criatividade em matemática é caracterizada pela "capacidade de apresentar diversas possibilidades de soluções apropriadas para uma situação-problema, de modo que estas focalizem aspectos distintos do problema e/ou formas diferenciadas de solucioná-lo, especialmente formas incomuns" [14]. Assim, a capacidade criativa em matemática caracterizase pela abundância de ideias diferentes produzidas sobre um mesmo assunto (fluência), pela capacidade de alterar o pensamento ou conceber diferentes categorias de resposta (flexibilidade) e por apresentar respostas infrequentes ou incomuns (originalidade) [1]. A fluência, flexibilidade e originalidade são denominadas "características latentes da criatividade em matemática", de modo que a criatividade em matemática pode ser analisada em função dessas características [35]. Convém destacar que Guilford definiu outras características latentes da criatividade. No entanto, neste trabalho a criatividade será avaliada 
em função da fluência, flexibilidade e originalidade, de acordo com o trabalho de Gontijo [14].

A fluência consiste na capacidade de produzir ideias, métodos, estratégias ou soluções para uma determinada situação-problema, expressando-se como a quantidade de respostas produzidas pelo indivíduo. A fluência do conhecimento é mais do que a memorização de fatos ou procedimentos, pois se assenta em uma sólida base de conhecimento bem organizado [36].

A flexibilidade consiste na quantidade de ideias distintas produzidas pelo individuo, dessa forma, há muita flexibilidade quando as ideias, ainda que poucas, apresentam características suficientes para pertencerem a categorias distintas. A flexibilidade de representação é uma característica do pensamento criativo que tem grande relevância na resolução de problemas, estando associada à capacidade de superar a rigidez de pensamento e romper com modelos mentais pré-construídos [10].

A originalidade refere-se à produção de respostas infrequentes, incomuns ou raras. Convém ressaltar que a originalidade é uma característica relativa e questionável para alguns pesquisadores, que distinguem a criatividade de uma ideia que ninguém teve antes de uma criatividade como uma ideia original de um indivíduo $[20 ; 21]$.

Neste trabalho, será considerada esta última definição de criatividade em matemática, ou seja, a definição proposta por Gontijo [14]. A partir dessa definição, serão apresentadas a seguir instrumentos para o desenvolvimento da criatividade em matemática, e, posteriormente, atividades para sala de aula para promover este desenvolvimento.

\section{4}

\section{Instrumentos para o desenvolvimento da criatividade em matemática}

Há muitos estudos sobre estratégias para o desenvolvimento da criatividade em matemática $[7 ; 14 ; 37 ; 38]$. Estes estudos, além de descreverem o processo criativo na matemática, definem como principais instrumentos para o seu desenvolvimento e análise a resolução de problemas (problem solving), a formulação de problemas (problem posing) e a redefinição (redefinition). Cada um desses três instrumentos serão explicados a seguir.

Um fato comum nos instrumentos para exercício da criatividade em matemática é que estes costumam trabalhar com problemas abertos, isso é, problemas ricos em caminhos e respostas possíveis [35]. Essa característica é fundamental, pois problemas que são solucionados por uma ou poucas estratégias não permitem a expressão das ideias com fluência, flexibilidade e originalidade. 
Além disso, cabe ressaltar que esses instrumentos auxiliam no desenvolvimento da criatividade em matemática, no entanto, não são os únicos fatores a serem considerados, uma vez que aspectos como a motivação do aluno, o ambiente em sala de aula e o incentivo para a participação do aluno são outros aspectos a serem considerados.

Inicialmente, este trabalho teve por intenção aplicar um teste de criatividade em matemática em sala de aula em alunos do $1^{\circ}$ ao $3^{\circ}$ ano do Ensino Médio, para medir a sua criatividade em matemática. Com os resultados obtidos, seria avaliado como varia a criatividade em matemática dos alunos ao longo dos anos escolares do Ensino Médio. No entanto, com a pandemia do Covid19 não foi possível a realização dessa pesquisa, uma vez que muitas escolas estavam com poucos dias na semana com aulas presenciais, não sendo permitidas pesquisas para evitar aglomerações e para não prejudicar o cronograma, que já se encontrava afetado. Por este motivo, sugere-se que esta atividade seja realizada posteriormente em outra pesquisa, dando continuidade a este estudo.

\subsection{1}

\section{Resolução de problemas}

A resolução de problemas consiste na resolução de questões não estruturadas, que não são resolvidas por uma técnica específica, permitindo ao aluno descobrir um caminho de resolução por uma série de operações mentais [14].

Há uma grande correlação entre a criatividade em matemática e a capacidade de resolução de problemas. Para que incentivem o aluno a desenvolver a criatividade, estes problemas não podem ser aplicações diretas de algoritmos ou fórmulas. Ao contrário, os problemas propostos devem permitir múltiplos métodos de solução e/ou respostas $[7 ; 38]$.

O exemplo a seguir ilustra uma resolução de problema, proposta por Gontijo [14]:

"Utilizando quatro números 4, realize operações entre esses números de modo que o resultado seja igual a 4".

Observe que o problema é aberto, permitindo múltiplas soluções. Algumas delas estão apresentadas a seguir:

$$
\begin{gathered}
(4-4) \cdot 4+4=4 \\
\sqrt{4+4+4+4}=4 \\
4 !-(4.4)-4=4 \\
\frac{\sqrt{4}^{\sqrt{4}}}{4} \cdot 4=4
\end{gathered}
$$




$$
\frac{(\sqrt{4}) ! .4}{4} \cdot \sqrt{4}=4
$$

Para este probema, com os quais Gontijo lista 59 resoluções diferentes, que foram propostas pelos pelos alunos que aplicou sua pesquisa (alunos do $3^{\circ}$ ano do Ensino Médio de uma escola da rede privada de Brasília-DF). No entanto, não são necessariamente as únicas soluções possíveis.

Uma vez que a criatividade em matemática pode ser analisada em função de suas caraterísticas latentes (fluência, flexibilidade e originalidade), podese analisar individualmente o nível de criatividade das respostas da seguinte forma:

1. Fluência: número de sentenças matemáticas que envolvem exclusivamente quatro números 4 e que produzam resultado igual a 4. Quanto mais sentenças matemáticas forem propostas pelo aluno, maior será a fluência.

2. Flexibilidade: número de categorias de sentenças, calculado pelo número de operações diferentes utilizadas em cada sentença elaborada. Quanto mais operações diferentes forem utilizadas, maior será a flexibilidade.

3. Originalidade: raridade relativa das sentenças elaboradas. Essa característica depende, portanto, das respostas dadas pelos outros alunos da pesquisa.

A resolução de problemas é destacada pelos PCN como um importante instrumento para desenvolver a capacidade de gerenciar informações pelo aluno e a autoconfiança:

A resolução de problemas, na perspectiva indicada pelos educadores matemáticos, possibilita aos alunos mobilizar conhecimentos e desenvolver a capacidade para gerenciar as informações que estão a seu alcance. Assim, os alunos terão oportunidade de ampliar seus conhecimentos acerca de conceitos e procedimentos matemáticos bem como de ampliar a visão que têm dos problemas, da Matemática, do mundo em geral e desenvolver sua autoconfiança $[4 ; 5]$.

Na resolução de problemas, a abordagem de situações diversas e complexas possibilitam que o aluno pense por si mesmo, construindo estratégias de resolução e argumentações, relacione conhecimentos diferentes e persevere na busca por uma solução do aluno. Além disso, a resolução de problemas pode despertar o interesse pela atividade matemática, propiciando o gosto pela descoberta da resolução, estimulando a curiosidade, a criatividade e o aprimoramento do conhecimento. 


\subsection{2}

\section{Formulação de problemas}

A formulação de problemas também consiste em uma forma de estímulo da criatividade do aluno.

O exemplo a seguir ilustra uma formulação de problema, proposta por Gontijo [14]:

"Considere a seguinte situação: Antônio, Bernardo e Carlos retornavam, de automóvel, para suas casas depois de uma viagem. Carlos dirigiu $140 \mathrm{~km}$ a mais que Bernardo. Bernardo dirigiu duas vezes o percurso percorrido por Antônio. Antônio dirigiu $90 \mathrm{~km}$. Elabore perguntas que podem ser respondidas baseadas nesse enunciado."

Observe que o problema é aberto, permitindo múltiplas soluções. Algumas delas estão apresentadas a seguir:

1. Quantos quilômetros Antônio dirigiu?

2. Qual a soma da quilometragem percorrida por Antônio e Bernardo?

3. Quantos quilômetros Carlos dirigiu a mais que Paulo?

4. Supondo que o carro gaste 0,1 litros por quilômetro percorrido, quanto Antônio gastou de combustível?

5. Sabendo que as velocidades médias de Antônio, Bernardo e Carlos eram $45 \mathrm{~km} / \mathrm{h}, 60 \mathrm{~km} / \mathrm{h}$ e $90 \mathrm{~km} / \mathrm{h}$, quantas horas cada um gastou no percurso?

Para este probema, com os quais Gontijo lista 72 resoluções diferentes, que foram propostas pelos alunos que aplicou sua pesquisa (alunos do $3^{\circ}$ ano do Ensino Médio de uma escola da rede privada de Brasília-DF), não sendo necessariamente as únicas soluções possíveis. Convém destacar que a pesquisa de Gontijo foi realizada entre alunos do Ensino Médio de uma escola da rede privada de ensino de Brasília-DF.

De acordo com Gontijo[14], pode-se analisar o nível de criatividade das respostas da seguinte forma, em função das características latentes da criatividade em matemática:

1. Fluência: número de problemas solucionáveis propostos pelo aluno.

2. Flexibilidade: número de relações semânticas envolvidas nas respostas. Essas relações semânticas podem estabelecer relações como, por exemplo, de reapresentação ("quantos quilômetros Antônio percorreu?"), de grupo ("quantos quilômetros os três andaram juntos?") ou de comparação ("quantos quilômetros Carlos dirigiu a mais que Paulo?"). 
3. Originalidade: raridade relativa das sentenças elaboradas. Essa característica depende, portanto, das respostas dadas pelos outros alunos da pesquisa.

Kilpatrick afirma sobre o uso da formulação de problemas na educação [39]:

"A experiência de descobrir e criar seus próprios problemas deveria ser parte da educação de todo estudante. Pelo contrário, ela é uma experiência que poucos estudantes têm hoje em dia - exceto talvez se eles forem candidatos a graus avançados em matemática [...] Pesquisadores, como os professores, tendem a ignorar os processos de criação e formulação de problemas."

Quando um estudante formula ou reformula um problema, é possível ter uma melhor percepção de como os estudantes estão compreendendo os conceitos e processos matemáticos ensinados, bem como sua atitude em relação à matemática e sua capacidade criativa.

A importância de exercitar a formulação de problemas com os alunos ocorre também pela sua relação com o processo de descoberta científica. Karl Popper e John Eccles buscaram explicar o processo de descoberta científica e concluíram que o processo de formulação de problemas e o processo real de produção ou descoberta de teorias e leis científicas são muito parecidos: ambos são processos de elaboração e verificação [40].

\subsection{3 \\ Redefinição}

A redefinição consiste em analisar uma situação matemática em termos de seus atributos, verificando similaridades, padrões e regras. São trabalhos de redefinição, por exemplo, solicitar que os alunos formem subconjuntos a partir de um conjunto dado, indicando a sua regra de formação e características comuns dos elementos. Outro exemplo consiste na apresentação de dois elementos, como números ou figuras geométricas, e solicitar que os alunos escrevam todas as características que observam em comum entre esses elementos.

O exemplo a seguir ilustra uma formulação de problema, proposta por Fonseca [35]:

Liste tantas características diferentes quanto puder observar entre um triângulo e uma pirâmide.

A tabela a seguir apresenta algumas respostas possíveis para a pergunta:

De acordo com Gontijo[14], os seguintes critérios podem ser adotados para analisar a fluência, flexibilidade e originalidade [35]:

a) Fluência: número de relações corretas estabelecidas; 
Tabela 2.1: Diferenças entre triângulo e pirâmide.

\begin{tabular}{|c|c|}
\hline TRIÂNGULO & PIRÂMIDE \\
\hline Bidimensional & Tridimensional \\
\hline Sua área é a área de sua única face & Sua área é a soma das áreas de suas faces \\
\hline $\mathrm{N}^{\circ}$ vértices igual ao de arestas & $\mathrm{N}^{\circ}$ de vértices diferente do de arestas \\
\hline Número fixo de arestas (3) & Número variável de arestas \\
\hline
\end{tabular}

b) Flexibilidade: a flexibilidade é avaliada conforme a alteração de categoria, sendo previamente estabelecidas categorias que abarquem as ideias geradas, como a forma de projeção, a área, os elementos (vértices, arestas e faces).

c) Originalidade: para avaliar a originalidade, é necessário aplicar o teste de criatividade a um grande grupo de alunos, identificando respostas infrequentes. 


\section{3}

\section{Exercitando a criatividade em matemática dos alunos}

Este capítulo tem por finalidade apresentar algumas atividades que tem como objetivo exercitar a criatividade dos alunos e que podem ser empregadas em sala de aula.

Para o desenvolvimento da criatividade em matemática, as atividades que envolvem problemas abertos, ou seja, ricas em diferentes possibilidades de resposta ou métodos de solução, exercem um papel importante para o seu desenvolvimento. Essas atividades não possuem a finalidade de verificar a capacidade do aluno em encontrar o caminho mais simples e rápido para chegar a uma resposta correta, mas na capacidade do aluno correlacionar informações, chegando nessa resposta. De fato, como afirmava Poincaré, a capacidade criativa no campo da matemática consiste na capacidade de correlacionar ideias conhecidas e escolher aquelas que são importantes.

Cabe também ressaltar a importância de criar em sala de aula um ambiente favorável para a criatividade, encorajando alunos para expressar suas ideias, fazendo ele se sentir acolhido e valorizado, pois, como citado anteriormente, o ambiente incentiva o desenvolvimento criativo do aluno.

\section{1 \\ Produções escritas}

Produções escritas, por meio das quais os alunos podem questionar e analisar suposições, além de proporem problemas com palavras, são ferramentas importantes para desenvolver a criatividade $[14 ; 1 ; 41]$.

Exemplo 1: os alunos podem fazer uma pesquisa sobre o sistema de numeração de base 10, analisando o seu desenvolvimento histórico, questionando por que esse sistema é o mais utilizado no mundo, e pesquisando outros sistemas de numeração com o seu campo de aplicação (por exemplo, o sistema binário e os computadores). Estudando sobre esses aspectos dos sistemas de numeração, o aluno exercita a criatividade se questionando sobre a realidade e pensando em novas possibilidades.

Exemplo 2: os alunos podem realizar pesquisas sobre as biografias dos matemáticos que contribuíram com a formulação do conteúdo que estão estudando. Com essa atividade, o aluno exercita a criatividade, relacionando 
os conteúdos matemáticos com o seu contexto histórico, sua evolução e sua relação com outros conhecimentos da época.

Exemplo 3: pode-se também propor aos alunos a formulação de problemas (fazer o aluno formular um problema que envolve determinado assunto) ou a redefinição (reorganizar ou classificar elementos em função de seus atributos). Essa atividade trabalha a criatividade do aluno, pois promove a fluência, através do número de relações estabelecidas, e a flexibilidade, através dos diferentes campos trabalhados.

Exemplo 4: este exemplo é retirado do capítulo anterior: "considere a seguinte situação: Antônio, Bernardo e Carlos retornavam, de automóvel, para suas casas depois de uma viagem. Carlos dirigiu $140 \mathrm{~km}$ a mais que Bernardo. Bernardo dirigiu duas vezes o percurso percorrido por Antônio. Antônio dirigiu $90 \mathrm{~km}$. Elabore perguntas que podem ser respondidas baseadas nesse enunciado". Assim como no exemplo 3, essa atividade exercita a criatividade pois promove o seu desenvolvimento através de suas características latentes

\section{2}

\section{Produções numéricas ou algébricas}

Produções numéricas ou algébricas, como a criação de algoritmos para as operações numéricas, explicando como estes funcionam, ou a realização de atividades que envolvem a percepção de padrões numéricos, são ferramentas para o desenvolvimento da criatividade $[14 ; 1 ; 41]$.

Exemplo 1: escrever sentenças matemáticas cujo resultado seja 4, utilizando exatamente 4 algarismos 4 e mais nenhum algarismo, além de operações matemáticas.

Quanto maior o número de sentenças matemáticas que envolvem exclusivamente quatro números 4 e que produzam resultado igual a 4 , maior a fluência. Quanto maior o número de operações diferentes utilizadas em cada sentença elaborada, maior a flexibilidade. E a originalidade é analisada pela raridade relativa das sentenças elaboradas.

O exemplo a seguir ilustra algumas respostas:

$$
\begin{gathered}
\sqrt{4+4+4+4}=4 \\
(4-4) \cdot 4+4=4 \\
\sqrt{4}+\sqrt{4}-4+4=4 \\
4 !-(4.4)-4=4 \\
4 \sqrt{4}-\sqrt{4}-\sqrt{4}=4
\end{gathered}
$$




$$
\begin{aligned}
& \frac{4 !-4-4}{4}=4 \\
& \frac{4 !}{4}+\sqrt{4}-4=4 \\
& \frac{4}{4} \cdot \sqrt{4}+\sqrt{4}=4
\end{aligned}
$$

Exemplo 2: considere os números inteiros de 2 a 16 (inclusive o 2 e o 16) e escreva os diversos subconjuntos que você puder estabelecer envolvendo estes números, indicando a regra para a formação de cada um deles, isto é, indicando as características que os números possuem e que fazem com que possam estar em um mesmo subconjunto.

Nessa atividade, a fluência é analisada pelo número de subconjuntos formados. E a flexibilidade é analisada pelo número de características dos elementos de cada subconjunto: números pares/ímpares, múltiplos/divisores, maiores que/menores que, primos, negação, interseção de vários atributos. A tabela a seguir apresenta algumas possíveis respostas:

\begin{tabular}{|c|c|}
\hline Subconjunto & Regra \\
\hline $3,5,7,9,11,13,15$ & Números ímpares \\
\hline $2,4,6,8,10,12,14,16$ & Números pares \\
\hline $3,6,9,12,15$ & Divisíveis por 3 \\
\hline $4,8,12,16$ & Divisíveis por 4 \\
\hline $2,3,5,7,11,13$ & Números primos \\
\hline $4,5,6,8,9,10,12,14,15,16$ & Números não primos \\
\hline $2,3,4,5,6,7,8,9$ & Menores que 10 \\
\hline $11,12,13,14,15,16$ & Maiores que 10 \\
\hline $2,4,8,16$ & Divisores de 32 \\
\hline $4,14,15$ & Números que começam com a letra q \\
\hline
\end{tabular}

\section{3}

\section{Representações gráficas e construções geométricas}

Com o uso de representações gráficas e construções geométricas, pode-se explorar o senso de proporção e simetria, visão espacial, compreensão e uso de perspectivas.

Exemplo 1: construir polígonos com perímetro 14 centímetros utilizando uma malha quadriculada de quadrados de $1 \mathrm{~cm}$ de lado.

Analisando em termos de fluência, quanto maior for o número de polígonos que satisfazem às condições do problema, maior será esta característica de criatividade. Em termos de flexibilidade, pode-se analisar o número de polígo- 
nos com áreas diferentes. E originalidade, a raridade relativa dos polígonos. A figura a seguir ilustra alguns exemplos:

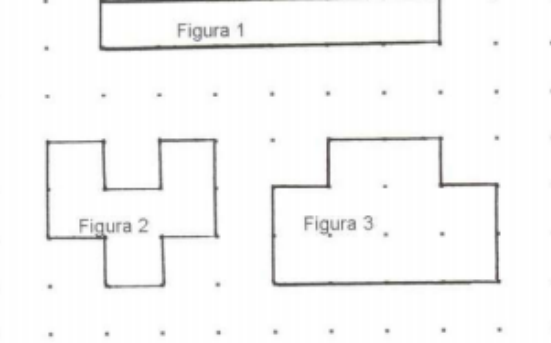

Todas as imagens antendem às condições do problema. As figuras 1 e 2 possuem área de $6 \mathrm{~cm}^{2}$, enquanto a figura 3 possui área de $10 \mathrm{~cm}^{2}$.

Segundo Smith, citado por Gontijo [14], pode-se obter um total de 137 polígonos diferentes com perímetro igual a $14 \mathrm{~cm}$, de modo que 4 desses polígonos possuem área igual a $4 \mathrm{~cm}^{2}, 12$ polígonos possuem área igual a $5 \mathrm{~cm}^{2}$, 38 possuem área igual a $6 \mathrm{~cm}^{2}, 32$ possuem área igual a $7 \mathrm{~cm}^{2}, 30$ possuem área igual a $8 \mathrm{~cm}^{2}, 12$ possuem área igual a $9 \mathrm{~cm}^{2}, 7$ possuem área igual a 10 $\mathrm{cm}^{2}, 1$ possui área de $11 \mathrm{~cm}^{2}$, e 1 cuja área mede $12 \mathrm{~cm}^{2}$.

Exemplo 2: dividir uma figura geométrica em uma determinada quantidade de partes, toda de mesmo tamanho. A questão a seguir apresenta um exemplo deste trabalho, proposto por Pinheiro [41], que envolve representações gráficas e construções geométricas:

A professora Ana decidiu fazer com seus alunos bandeirinhas para enfeitar a festa da vila. Propôs alguns materiais para a sua construção: folhas de papel retangulares brancas, marcadores ou lápis de cor, cola, régua, palitos ou palhinhas e instruções para a sua construção.

Cada aluno teria de dividir a folha de papel em partes geometricamente iguais, tantas quanta conseguisse, de acordo com o país: país dos meios, país dos terços, e país dos quartos. Depois de dividir o papel teriam de colorir cada uma com diferentes cores e construir noutro papel um dístico com o nome do país.

Apresente as diferentes possibilidades de construir as bandeiras do país dos meios, dos terços e dos quartos. [41].

Espera-se dos alunos uma representação da bandeira para o "país dos meios"dividida em duas partes iguais por meio de uma repartição na horizontal, vertical ou diagonal. Para o "país dos terços", espera-se uma bandeira dividida em três partes por repartições na horizontal ou vertical. E para o "país dos quartos", repartições na horizontal e/ou vertical. Pinheiro [41] destacou em 
sua pesquisa algumas resoluções originais no papel quadriculado, apresentadas nas figuras a seguir.

Figura 3.1: Respostas comuns para o país dos meios

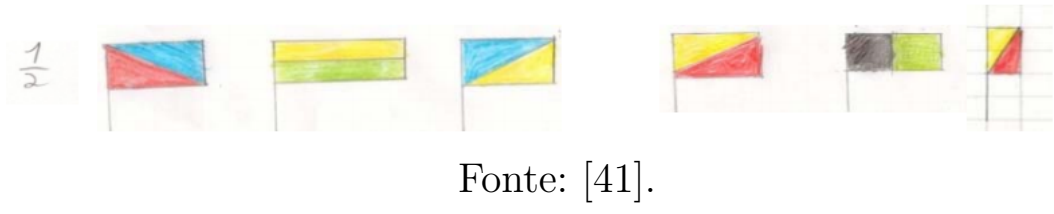

Figura 3.2: Resposta incomum para o país dos meios

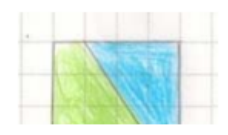

Fonte: [41].

Figura 3.3: Respostas comuns para o país dos terços e dos quartos
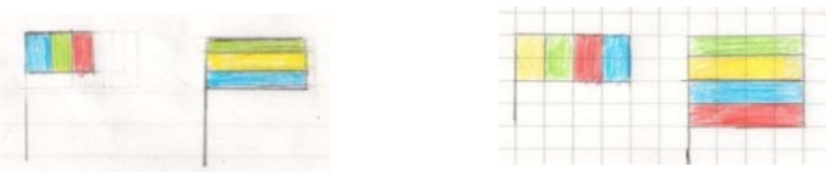

Fonte: [41].

Figura 3.4: Respostas incomuns para o país dos terços e quartos
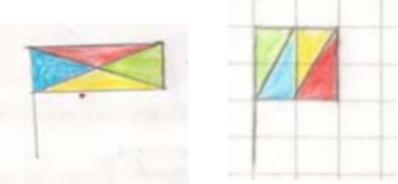

Fonte: [41].

Por fim, são apresentados a seguir quatro questões do Canguru de Matemática ${ }^{1}$.

As questões apresentadas podem ser trabalhadas em sala de aula para o exercício da criatividade. Essas questões foram selecionadas pois trabalham com a criatividade, em virtude de permitir uma flexibilidade de pensamento, podendo chegar à resposta final por diferentes caminhos. Além disso, essas questões são ricas nas possibilidades de fazer tentativas.

${ }^{1}$ O Canguru de Matemática é uma competição de Matemática de abrangência internacional, destinada para alunos do $3^{\circ}$ ano do Ensino Fundamental ao $3^{\circ}$ ano do Ensino Médio. Ela teve origem em 1991 na França, e é administrada globalmente pela Associação Canguru sem Fronteiras (Association Kangourou sans Frontières - AKSF). 
A primeira questão apresentada foi proposta em uma prova para alunos do $3^{\circ}$ e $4^{\circ}$ ano do Ensino Fundamental II; a segunda e terceira questões, para alunos do $5^{\circ}$ e $6^{\circ}$ ano do Ensino Fundamental II; e a quarta questão, para alunos do $7^{\circ}$ e $8^{\circ}$ ano do Ensino Fundamental II. No entanto, dependendo do tipo de abordagem, essas questões podem ser abordadas em anos escolares diferentes.

Por fim, outras questões do Canguru de Matemática, com suas respectivas soluções, podem ser obtidas no site: https://www.cangurudematematicabrasil.com.br/para-escolas/provasanteriores.html

Questão Canguru 1: Todas as noites o mago Tilim faz a previsão do tempo para o rei. Quando Tilim acerta, recebe 3 moedas de ouro, mas quando erra, paga uma multa de 2 moedas de ouro. Depois de fazer a previsão por 5 dias, Tilim fez as contas e descobriu que nem ganhou nem perdeu moedas. Quantas vezes ele acertou a previsão nesses 5 dias?

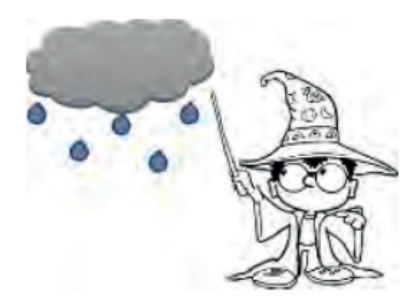

Nessa questão, o aluno poderá fazer tentativas até chegar à resposta final. Se o mago acertou todos os dias a previsão, então teria ganho:

$$
3 \times 5=15
$$

Se o mago acertou 4 dias a previsão, então teria ganho:

$$
3 \times 4-2 \times 1=10
$$

Se o mago acertou 3 dias a previsão, então teria ganho:

$$
3 \times 3-2 \times 2=5
$$

Se o mago acertou 2 dias a previsão, então teria ganho:

$$
3 \times 2-2 \times 3=0
$$

Portanto, conclui-se que o mago acertou 2 dias a previsão.

Essa questão pode também ser trabalhada com alunos do $8^{\circ}$ e $9^{\circ}$ ano, como uma introdução ao estudo de expressões algébricas. Nesse caso, pode-se 
considerar x como o número de dias que acertou a previsão, desse modo, em 5 - $\mathrm{x}$ dias ele errou.

Com isso, obtemos a seguinte resolução:

$$
\begin{gathered}
3 . x-2 .(5-x)=0 \\
3 x-10+2 x=0 \\
x=2
\end{gathered}
$$

Portanto, o mago acertou a previsão do tempo dois dias.

Questão Canguru 2: Mônica escreve números na figura ao lado de modo que cada número escrito em cada quadradinho é igual ao produto dos números escritos nos dois quadradinhos abaixo dele, quando houver. Qual número ela deve escrever no quadradinho escuro?

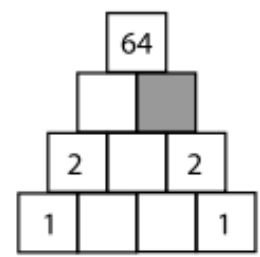

Nessa questão, o aluno poderá completar, inicialmente, os números dos quadrados da base da pirâmide. A partir deles, poderá descobrir os números dos quadrados superiores. Observe a imagem a seguir, que apresenta essa resolução.

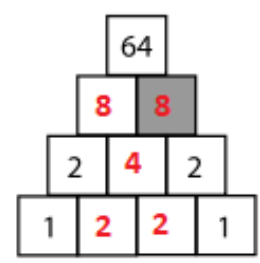

Questão Canguru 3: Qual número deve ser escrito no círculo com o ponto de interrogação?

Qualquer que seja o número inserido onde está a interrogação, ao ser multiplicado por zero, resultará em zero. Então, realizando as operações das setas seguintes, temos:

$$
\begin{aligned}
& 0+6=6 \\
& 6 \times 4=24
\end{aligned}
$$




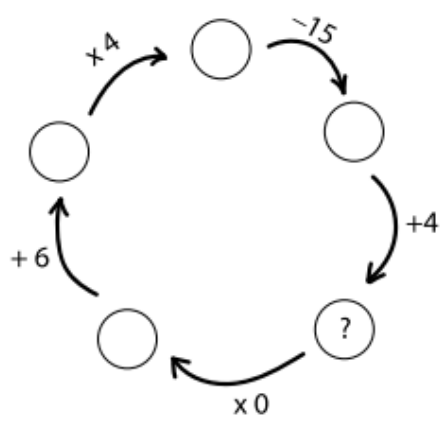

$$
\begin{aligned}
& 24-15=9 \\
& 9+4=13
\end{aligned}
$$

Portanto, o número procurado é igual a 13.

Questão Canguru 4: A soma dos pontos das faces opostas de um dado comum é 7 . Esse dado é colocado no primeiro quadrado conforme a figura e depois é rolado conforme indicado na figura, até o quinto quadrado. Quando o dado chega até o último quadrado, qual é o produto dos números de pontos mostrados nas duas faces verticais coloridas?

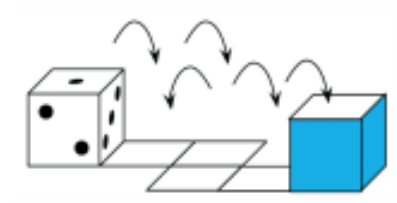

Essa questão trabalha com a visão espacial do aluno. Temos que, nos dois primeiros rolamentos, a face com o número 2 continua voltada para a frente. Portanto, a face com número 5 permanece. Após o primeiro rolamento, a face da direita mostra 1 ponto e a face de cima mostra 4 pontos. Após o segundo rolamento, a face da direita mostra 4 pontos e a face de cima mostra 6 pontos. No terceiro rolamento, a face da direita, com 4 pontos, permanece. Portanto, a face da esquerda, com 3 pontos, também não muda. Após o terceiro rolamento, a face da frente mostra 6 pontos e a face de trás, 1 ponto; a face de cima mostra 5 pontos e a face encostada no quadrado tem 2 pontos. Nos dois últimos rolamentos, a face da frente, com 6 pontos, permanece. Portanto, a face do fundo, com 1 ponto, também não muda. Após o quarto rolamento, a face da direita mostra 5 pontos e a face de cima mostra 3 pontos. Após o quinto rolamento, a face da direita mostra 3 pontos e a face de cima mostra 2 pontos. Logo, o produto dos pontos mostrados nas duas faces verticais coloridas é 


$$
6 \times 3=18 .
$$




\section{4}

\section{Considerações finais}

Neste trabalho, foi possível apresentar uma pesquisa bibliográfica sobre o conceito de criatividade e criatividade em matemática, expondo a importância dessas habilidades. Foi possível mostrar a complexidade envolvida no conceito de criatividade, por ser um conceito que vem sendo desenvolvido e ampliado ao longo dos anos.

É importante destacar que a criatividade em matemática não é uma habilidade distinta da criatividade. A criatividade em matemática nada mais é do que a manifestação da criatividade no campo da matemática.

Algumas considerações a respeito da criatividade podem ser destacadas:

a) A criatividade é uma importante habilidade para ser desenvolvida nos alunos, surgindo de sua importância para a resolução de problemas e o aprimoramento individual e social, promovendo a capacidade de apresentar soluções inovadoras para os problemas da sociedade.

b) A criatividade não é uma habilidade restrita ao campo da matemática, abrangendo muitas outras áreas do conhecimento. É uma habilidade do intelecto humano, que permeia os diversos campos do conhecimento, de modo que é possível observar um trabalho criativo na arte, na música, na produção tecnológica, dentre outros, e que pode ser desenvolvida ou, ao contrário, reprimida. A criatividade não é algo que ocorre exclusivamente dentro da mente do indivíduo, que não depende e não se relaciona com o meio, mas sim um fenômeno com multiplas dimensões: individuo, processo, produto, contexto.

c) A escola desempenha um importante papel no desenvolvimento da criatividade. Para a formação de jovens mais criativos e com capacidade de apresentar soluções inovadoras, torna-se necessário incluir no planejamento da educação básica práticas escolares para desenvolver a criatividade.

d) O exercício da criatividade não se mostra como uma tarefa fácil. Vários fatores contribuem no seu exercício e desenvolvimento. Dessa forma, o simples exercício de atividades de criatividade em matemática não é suficiente para desenvolver a criatividade do aluno, quando não se consideram outros fatores relacionados com este desenvolvimento. Convém ressaltar que criar um ambiente em que alunos possam expressar suas ideias, se sintam acolhidos e valorizados é fundamental para o desenvolvimento de seu potencial criativo. 
Os pais e familiares dos alunos também devem contribuir nesse processo, incentivando a expressão de destes.

A fim de aprimorar a pesquisa, dando prosseguimento a este trabalho, as seguintes sugestões são fornecidas:

a) Realizar algumas das atividades propostas para exercitar a criatividade em matemática, seguido de um questionário sobre a opinião dos alunos sobre a atividade;

b) Avaliar, com o uso de um instrumento de avaliação de criatividade em matemática, como varia a criatividade em matemática dos alunos ao longo dos anos escolares;

c) Avaliar como varia a criatividade em matemática em escolas com diferentes pedagogias (tradicional, construtivista, montessoriana, etc);

d) Avaliar como varia a criatividade em matemática entre escolas públicas e particulares;

e) Avaliar se a premiação influencia na criatividade em matematica.

Aprimorando esta pesquisa, é possível ter um conhecimento mais profundo da criatividade e de caminhos para o seu desenvolvimento nos alunos.

Para aprofundar os conhecimentos sobre pesquisas em criatividade em matemática, os seguintes links são recomendados:

a) Grupo Pi - Pesquisas e Investigações em Educação Matemática:

https://sites.google.com/view/grupopibsb/p\%C3\%A1gina-inicial.

b) Canal do Youtube do grupo Pi -

https://www.youtube.com/channel/UC3pJbppvjBP_1Mip_jEHQrQ. 


\section{Referências}

[1] GONTIJO, C. H.. Criatividade em matemática: conceitos, metodologias e formas de avaliação. Educação Matemática, Cultura e Diversidade. 2010.

[2] GONTIJO, C.. Criatividade em matemática: identificação e promoção de talentos criativos. Revista do Centro de Educação, vol. 32, núm. 2, 2007, pp. 481-494. 2007.

[3] BRASIL. Base nacional comum curricular - ensino fundamental. 2015.

[4] BRASIL. Parâmetros curriculares nacionais. 2015.

[5] BRASIL. Parâmetros curriculares nacionais. 2015.

[6] ALENCAR, E.. Escala sobre o clima para criatividade em sala de aula. Psicologia: Teoria e Pesquisa. Jan-Abr 2005, Vol. 21 n. 1, pp. 085-091. 2005.

[7] KWON, O. N.; PARK, J. P. J.. Cultivating divergent thinking in mathematics through open-ended approach. Asia Pacific Education Review, Vol. 7, No 1, 51-61. 2006.

[8] STERNBERG, R. J.. The nature of creativity. Creativity Research Journal, vol 18, n. 1, p. 87-98. 2006.

[9] GRÉGOIRE, J.. Understanding creativity in mathematics for improving mathematical education. Journal of Cognitive Education and Psychology Volume 15, Number 1, 2016.

[10] AMARAL, N.; CARREIRA, S.. A criatividade matemática nas respostas de alunos participantes de uma competição de resolução de problemas. Bolema, Rio Claro (SP), v. 31, n. 59, p. 880-906, dez. 2017. 2017.

[11] KARKOCKIENE, D.. Nurturing creativity in the micro-moments of the classroom. International Journal of Educology, (Lithuanian, Special Issue), Sydney, p. 51-58. 2005. 
[12] KIM, K. H.. Creatively gifted students are not like other gifted students: Research, theory, and practice. Rotterdam, Netherlands: Sense Publishers, 2013. p. 3-15. 2013.

[13] PINHO, J.L.R.; MORETTI, M.. Estimulando a criatividade em matemática em sala de aula através da formulação e resolução de problemas em geometria. Revista de Matemática, Ensino e Cultura, ano 13 - mai/ago 2018. 2018.

[14] GONTIJO, C. H.. Relações entre criatividade, criatividade em matemática e motivação em matemática de alunos do ensino médio. PhD thesis, Universidade de Brasília, Brasília, 2007.

[15] HADAMARD, J.. Essay on the psychology of invention in the mathematical field. Princenton University Press. Princeton, NJ. 1949.

[16] MUMFORD, M.D; GUSTAFSON, S.. Creativity syndrome: Integration, application and innovation. Psychological Bulletin. 1988.

[17] CSIKSZENTMIHALYI, M.. Flow and the psychology of discovery and invention. New York, NY: Harper Collins Pub. 1996.

[18] SILVER, E. A.. Fostering creativity through instruction rich in mathematical problem solving and problem posing. ZDM - The International Journal on Mathematics Education, vol. 29, n. 3, p. 75-80. 1997.

[19] VINCENT-LANCRIN, S. E. A.. Fostering student's creativity and critical thinking: What it means in school. Educational Research and Innovation, OECD Publishing, Paris, 2019.

[20] BODEN, M.. The creative mind - myths and mechanisms. Londres: Routlege, 2nd ed. 2004.

[21] PAPAlEONTIOU-LOUCA, E.; VARNAVA-MAROUCHOU, D. M. S. K. E.. Teaching for creativity in universities. Journal of Education and Human Development, vol 3, n.4,p. 131-154. 2014.

[22] COHEN, L.. Developing children's creativity, thinking, and interests. strategies for the district, school, and classroom. OSSC Bulletin. 2013.

[23] ALACAPINAR, F. G.. Grade level and creativity. Egitim ArastirmalariEurasian Journal of Educational Research. 50, 247-266. 2013. 
[24] MOSER, J. E. A.. Mind your errors: evidence for a neural mechanism linking growth mindset to adaptive post error adjustements. Psychological Science, v. 22, p. 1484-1489, 2011.

[25] MANGELS, J. E. A.. Why do beliefs about intelligence influence learning success? a social cognitive neuroscience model. Social Cognitive and Affective Neuroscience, v.1, n. 2, p. 75-86, 2006.

[26] AMABILE, T.. Social influences on creativity: The effects of contracted-for reward. Egitim Arastirmalari-Eurasian Journal of Educational Research. 50, 247-266. 2013.

[27] PEREIRA, K.. A relação entre conhecimento e criatividade: evidências a partir de pesquisas com o jogo de xadrez. Ciências Cognição, v. 16, n. 1, 30 mar. 2011.

[28] RUNCO, M.. A longitudinal study of exceptional giftedness and creativity. 1999 .

[29] CLAXTON, A.F.; PANNELS, T. R. P.. Developmental trends in the creativity of school-age children. 2005.

[30] GARDNER, H.. Art, mind, and brain: A cognitive approach to creativity. 1982.

[31] BRITO, R.F.; VANZIN, T. U. V.. Reflexões sobre o conceito de criatividade: sua relação com a biologia do conhecer. Ciênc. cogn., Rio de Janeiro , v. 14, n. 3, p. 204-213, nov. 2009 . Disponível em <http://pepsic.bvsalud.org/scielo.php?script=sci_arttext\&pid=S180658212009000300017 lng $=$ ptnrm $=$ iso $>$. acessos em 13 out. 2021.

[32] NADJAFIKHAH, M.; YAFTIAN, N. B. S.. Mathematical creativity: some definitions and characteristics. 2011.

[33] SRIRAMAN, B.. Are giftdness \& creativity synonyms in mathematics? an annalysis of constructs within the professional and school realms. 2005.

[34] LILJEDAHL, P; SRIRAMAN, B.. Musings on mathematical creativity. 2006.

[35] FONSECA, M.G.; GONTIJO, C. S. J.. Criatividade no campo da matemática - como identificar e medir? Anais do Simpósio Internacional de Pesquisa em Educação Matemática, 4 , 2015, Ilhéus, Anais . Ilhéus, Bahia, Brasil. p. 2306-2311, ISSN 2446-6336. 2015. 
[36] NCTM. Procedural fluency in mathematics: A position of the national council of teachers of mathematics. Reston: NCTM, 2014. Disponível em: <http://www.nctm.org/about/content. asp x?id=42833>. 1997.

[37] SAK, U.; MAKER, C.. Developmental variation in children's creative mathematical thinking as a function of schooling, age and knowledge. Creativity Research Journal, vol. 18, No. 3, 279-291. 2006.

[38] TYAGI, T.. A study to examine the relationship between mathematical creativity and mathematical problem-solving performance. Journal of Indian Education, Vol XXXI, No 3, 80-89. 2015.

[39] KILPATRICK, J.. Problem formulating: Where do good problems come from? In A. H. Schoenfeld (Ed.). Cognitive science and mathematics education, Hillsdale, NJ: 1987. p. 123-147. 1987.

[40] SINGER, F. M.; ELLERTON, N. C. J.. Problem-posing research in mathematics education: new questions and directions. Educational Studies in Mathematics, v. 83, n.1, p. 1-7. 2013.

[41] PINHEIRO, S.; VALE, I.. Criatividade em matemática: um caminho partilhado. Academia.edu, 2015. Disponível em: $<$ https://www.academia.edu/7174953/CriatividadeeMatem\%C3>. Acesso em 24 de ago. de 2021. 